\title{
Survey of construction workers repeatedly exposed to chlorine over a three to six month period in a pulpmill: II. Follow up of affected workers by questionnaire, spirometry, and assessment of bronchial responsiveness 18 to 24 months after exposure ended
}

Luc Bhérer, Robert Cushman, Jean-Pierre Courteau, Michèle Quévillon, Gilles Côté, Jean Bourbeau, Jocelyne L'Archevêque, André Cartier, Jean-Luc Malo

\begin{abstract}
Objective-The aim was to determine the prevalence of persistent respiratory symptoms and bronchial hyper-responsiveness due to reactive airways dysfunction syndrome in a population of construction workers at moderate to high risk of developing the syndrome, at an interval of 18 to 24 months after multiple exposures to chlorine gas during renovations to a pulp and paper mill.

Design and participants-71 of 289 exposed workers $(25 \%)$ were identified on the basis of an exposure and the onset of respiratory symptoms shortly after this event (moderate to high risk). A standardised respiratory questionnaire was first presented, followed by spirometry and a methacholine inhalation test on those whose questionnaire suggested the persistence of respiratory symptoms.

Results-64 of 71 (90\%) subjects completed the respiratory questionnaire at the time of the follow up. The questionnaire suggested a persistence of respiratory symptoms in 58 of the 64 workers $(91 \%)$. Of the 58 subjects, 51 underwent spirometry and assessment of bronchial responsiveness. All of them used bronchodilators as required (not regularly) and four required inhaled antiinflammatory preparations. Sixteen had bronchial obstruction (forced expiratory volume in one second) $\left(\mathrm{FEV}_{1}<\mathbf{8 0 \%}\right.$ predicted) and 29 showed significant bronchial hyper-responsiveness.

Conclusion-Of the subjects $(n=71)$ who were at moderate to high risk of developing reactive airways dysfunction syndrome after being exposed to chlorine and were seen 18 to 24 months after exposure ended, $58(82 \%)$ still had respiratory symptoms, $16(23 \%)$ had evidence of bronchial obstruction, and 29 (41\%) had bronchial hyper-responsiveness.
\end{abstract}

(Occup Environ Med 1994;51:225-228)

Occupational health hazards at pulp and paper mills include exposure to irritant gases such as chlorine, chlorine dioxide, hydrochloric acid, sulphur dioxide, and hydrogen sulphide. The dangers of chlorine inhalation are well documented. ${ }^{12}$ In 1985, Brooks et al described a new condition that they called reactive airways dysfunction syndrome, the symptoms of which are the onset of cough, shortness of breath, and wheezing after a single inhalational exposure to high concentrations of toxic products. ${ }^{3}$ This condition, which is also referred to as irritant induced asthma, ${ }^{4}$ is characterised by the presence of asthma like symptoms and non-specific bronchial hyper-responsiveness in subjects who have no previous history of asthma. Others had previously described a similar type of syndrome after toxic inhalation ${ }^{5-9}$ and more recent case reports have been published. ${ }^{10-12}$ Several products can cause this syndrome-for example, chlorine, ammonia, acid fumes and sulphur dioxide.

The natural history in terms of the persistence of symptoms and bronchial hyperresponsiveness among subjects who were repeatedly exposed to high concentrations of chlorine is uncertain. Some cross sectional surveys in pulpmills show either no or only slight airway obstruction in workers chronically exposed to chlorine. ${ }^{121314}$ Follow up studies of workers accidentally exposed to chlorine show the persistence of airflow obstruction and functional respiratory changes only in a few of them ${ }^{715-17}$ although a larger proportion of subjects can be left with persistent bronchial hyper-responsiveness. ${ }^{18}$ Kern investigated 56 workers who had been exposed to high concentrations of glacial acetic acid. ${ }^{19}$ Only 24 of them (47\%) underwent a methacholine inhalation test eight months after the accident, and the author found a dose dependent relation between the magnitude of exposure and the likelihood of persistence of bronchial hyper-responsiveness. The effect of treatment, in particular, antiinflammatory preparations (oral and inhaled steroids), is also unknown.

The aim of this study was to assess the prevalence of persistent respiratory symptoms and bronchial responsiveness in a group of 71 construction workers at a pulpmill who were at moderate to high risk of developing 
reactive airways dysfunction syndrome $18-24$ months after repeated exposure to chlorine, as was ascertained in another study. ${ }^{20}$ This study, which included 257 workers (participation rate of $97 \%$ ) involved in welding and pipefitting procedures in the bleach plant where chlorine gas puffs were released, showed that $78 \%$ of them experienced throat irritation, $77 \%$ eye irritation, and $67 \%$ cough. A flu like syndrome with a mean duration of 19 days occurred in $63 \%$ of subjects. Dyspnoea was significantly more common in subjects who had reported at least once to the first aid station.

\section{Materials and methods \\ SUBJECTS}

From the initial population of 289 exposed workers, we selected 71 subjects $(25 \%)$ for medical follow up 18 to 24 months after the initial investigation (figure). The selection was based on the fact that there seems to be a dose dependent relation for the risk of developing respiratory airways dysfunction syndrome $^{19}$ and on the initial questionnaire, which showed these subjects to be at moderate to high risk of being affected with this syndrome. ${ }^{20}$ Those at moderate to high risks had: (1) in the case of moderate risk, either shortness of breath after the exposure period ended but no longer present at the time of the initial assessment (one month after the event) as well as significant other medical conditions, and/or age $\geqslant 50 ;(2)$ in the case of high risk, persistent shortness of breath one month after the accidental exposure and/or abnormal lung sounds.

\section{QUESTIONNAIRE}

A trained interviewer gave a questionnaire derived from the International Union against Tuberculosis and Lung Diseases (IUATLD). ${ }^{21}$ Also, information was gathered

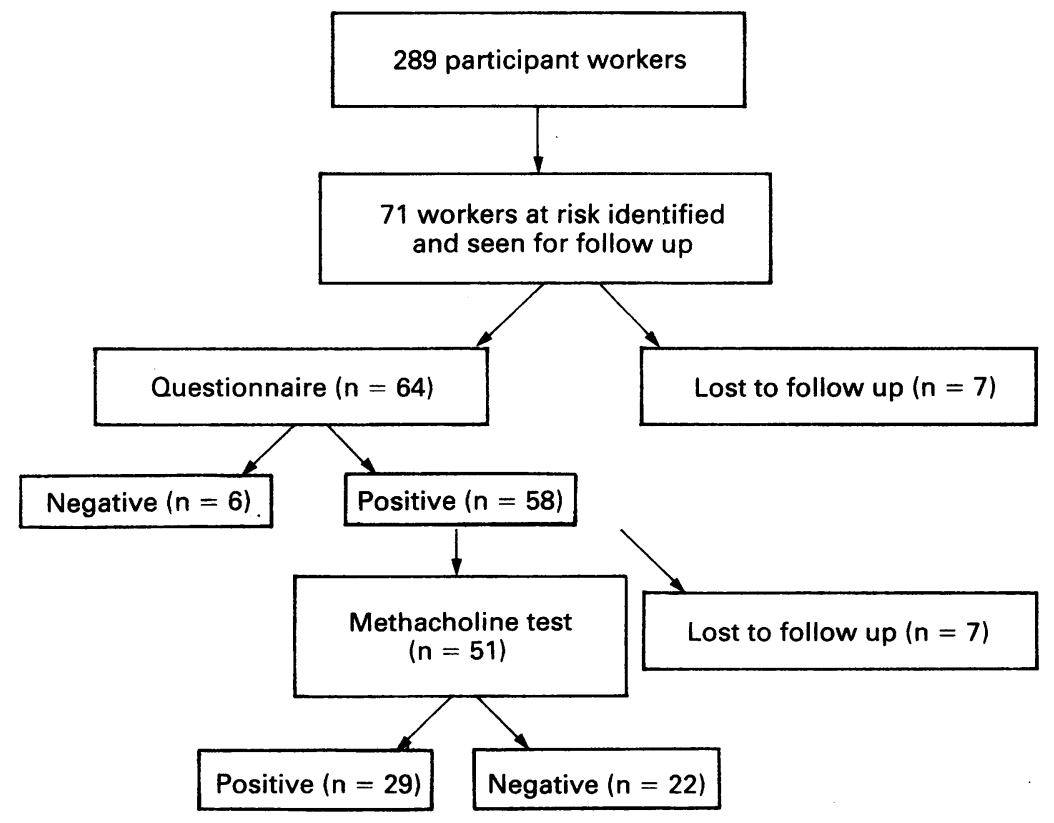

Figure Number of participants with abnormal results at each step of the study. on acute symptomatology and number of accidental exposures while the workers were employed (three to six month interval).

\section{SPIROMETRY AND ASSESSMENT OF}

NON-SPECIFIC BRONCHIAL RESPONSIVENESS

Spirometry was assessed according to the criteria of the American Thoracic Society. ${ }^{22}$ A methacholine inhalation test was carried out according to a standardised method (output of the nebuliser $=0.14 \mathrm{ml} / \mathrm{min}) .^{23}$ The concentration of methacholine causing a $20 \%$ fall in forced expiratory volume in one second $\left(F V_{1}\right)\left(P_{20}\right)$ was interpolated from the individual dose-response curve drawn on a semilogarithmic scale.

\section{ANALYSIS OF RESULTS}

Reference values for spirometry were obtained from Knudson and coworkers. ${ }^{24}$ $\mathrm{PC}_{20}$ levels $>16 \mathrm{mg} / \mathrm{ml}$ were considered to be normal. ${ }^{25}$

\section{STATISTICAL ANALYSIS}

A comparison was made between functional results and various demographic and clinical data using a $\chi^{2}$ distribution and unpaired $t$ tests. A $\mathrm{p}$ value $<0.05$ was considered significant.

\section{Results}

As shown in the figure 71 workers at risk were identified and approached for the follow up assessment. Seven were unavailable. The questionnaire suggested a persistence of respiratory symptoms in 58 workers $(82 \%)$. Fifty two of the 58 workers with a questionnaire suggestive of persistent respiratory symptoms agreed to undergo spirometry and methacholine inhalation testing. The other six subjects were unavailable.

The table lists some relevant anthropometric, clinical, and functional characteristics of subjects with significant airways obstruction and bronchial hyper-responsiveness. Only four subjects had taken or were still taking inhaled anti-inflammatory medication (corticosteroids) at the time of the survey. Sixteen subjects $(23 \%)$ still had bronchial obstruction and $29(41 \%)$, bronchial hyperresponsiveness. Neither age, smoking habits, number of accidental exposures nor initial symptoms differed between those with and without airway obstruction. The same applies to subjects with and without significant bronchial hyper-responsiveness. As expected, a previous history of asthma was found more often among subjects with airway obstruction or hyper-responsiveness. These subjects also tended to require more inhaled antiinflammatory preparations. As expected, those with a lower $\mathbf{P C}_{20}$ had significantly lower baseline FEV $_{1}$ and about half the subjects in this category $(15$ of $29,52 \%)$ had an $\mathrm{FEV}_{1}<80 \%$ predicted. Only one subject with normal bronchial responsiveness had an $\mathrm{FEV}_{1}$ value lower than $80 \%$ predicted.

The number of visits to a hospital emergency room was a significant predictor of the 
Table Anthropometric and clinical data according to results of spirometry and bronchial responsiveness to methacholine

\begin{tabular}{|c|c|c|c|c|}
\hline & \multicolumn{2}{|c|}{$F E V_{1}$ : percentage of predicted value } & \multicolumn{2}{|l|}{$P C 20$} \\
\hline & $<80 \%$ & $\geqslant 80 \%$ & $\leqslant 16 \mathrm{mg} / \mathrm{ml}$ & $>16 \mathrm{mg} / \mathrm{m}$ \\
\hline $\begin{array}{l}\text { Number } \\
\text { Age (y, mean (range)) }\end{array}$ & $\begin{array}{l}16 \\
50(29-62)\end{array}$ & $\begin{array}{l}35 \\
44(23-61)\end{array}$ & $\begin{array}{l}29 \\
47(23-62)\end{array}$ & $\begin{array}{l}22 \\
43(27-61)\end{array}$ \\
\hline $\begin{array}{l}\text { Smoking habits: } \\
\text { Smokers/ex-smokers/non-smokers } \\
\text { History of asthma }\end{array}$ & $\begin{array}{c}7 / 8 / 1 \\
5^{\star}\end{array}$ & $\begin{array}{l}20 / 12 / 3 \\
2\end{array}$ & $\begin{array}{l}15 / 12 / 2 \\
6 \dagger\end{array}$ & $12 / 8 / 2$ \\
\hline $\begin{array}{l}\text { Medication: } \\
\text { Bronchodilators only } \\
\text { Bronchodilators }+ \text { anti-inflammatory drugs } \\
\text { Accidental exposures ( } \mathrm{n} \text {, mean (range)) } \\
\text { Initial symptoms of dyspnoea } \\
\text { Initial symptoms of cough } \\
\text { Initial symptoms of dyspnoea and/or cough } \\
\text { FEV } \\
\text { FEV value (mean }(\text { SD) }) \\
\text { FE }<80 \% \text { predicted) }\end{array}$ & $\begin{array}{l}13 \\
3 \ddagger \\
36(2-120) \\
13 \\
15 \\
16\end{array}$ & $\begin{array}{l}34 \\
1 \\
55(2-240) \\
31 \\
32 \\
35\end{array}$ & $\begin{array}{l}25 \\
45 \\
45(2-180) \\
25 \\
26 \\
29 \\
2 \cdot 9(0 \cdot 9) 9 \\
15^{\star \star}\end{array}$ & $\begin{array}{l}22 \\
0 \\
58(2-240) \\
19 \\
21 \\
22 \\
3 \cdot 7(0 \cdot 7) \\
1\end{array}$ \\
\hline
\end{tabular}

likelihood of being left with persistent bronchial hyper-responsiveness. The mean number of visits to the hospital was 0.7 (SD 1.3) among subjects with persistent bronchial hyperresponsiveness as opposed to 0.07 $(0 \cdot 27)$ in those without bronchial hyperresponsiveness $(t=2 \cdot 4, p=0 \cdot 02)$. There was also a difference of borderline significance in the number of subjects who had been to an emergency room because of breathing problems after inhaling chlorine at work-namely, 12 subjects in the methacholine positive group as opposed to only three in the methacholine negative group $\left(\chi^{2}=3 \cdot 4, \mathrm{p}=0.06\right)$.

\section{Discussion}

In 1985, Brooks et al labelled a syndrome which consisted of persistent asthmatic symptoms with airway obstruction or hyperresponsiveness among subjects who had been exposed to high levels of irritant gas and aerosol, reactive airways dysfunction syndrome. $^{3}$ This is now included in one definition of occupational asthma. ${ }^{4}$

The functional behaviour of subjects exposed to high concentrations of irritant gases such as chlorine has not previously been exhaustively investigated through a combination of spirometry and bronchial responsiveness. From a cohort of 289 workers who had been exposed to chlorine 18 to 24 months before, we identified 71 workers who were judged to be at high or moderate risk based on clinical history and physical signs (chest auscultation). Ideally, we would have been interested in investigating the entire cohort of 289 workers. Workers moved back to their original areas, however, after having worked for three to six months in the plant where repeated exposures to chlorine occurred. This means that they were dispersed over various parts of Quebec. This precluded using all subjects in the follow up survey. We were nevertheless able to question most of the subjects judged to be at moderate to high risk (64 of $71,90 \%$ ) 18 to 24 months after exposure ended. Most were still symptomatic. Spirometry and bronchial responsiveness could be assessed in 51 of the 58 subjects $(88 \%)$, so the participation rate was satisfactory. It is therefore unlikely that results of our study could have been biased by a lack of par- ticipation. We found that 16 of $51(31 \%)$ of those who underwent objective testing (23\% of the selected group of 71 subjects) had airways obstruction. Few data on the long term functional behaviour of reactive airways dysfunction syndrome have been published. Kaufman et $\mathrm{al}^{15}$ found that four of 18 subjects $(22 \%)$ had persistent airways obstruction 12 to 14 months after inhaling chlorine. Charan and coworkers found that three of 11 (27\%) workers exposed to chlorine had airways obstruction about two years later. ${ }^{17}$ Schwartz et al reported that about $40 \%$ of subjects accidentally exposed to high concentrations of chlorine had airways obstruction two years after the event. ${ }^{18}$ Therefore, the proportion of subjects with persistent airways obstruction in our study $(31 \%$ or $23 \%$ depending on the denominator) is close to that previously found in smaller groups of subjects.

To the best of our knowledge, only two other studies have examined bronchial hyperresponsiveness after acute exposure to irritant gas. Data were obtained in smaller groups of subjects and at different time intervals after the irritant inhalation. Bronchial hyperresponsiveness is a key feature of asthma. In most instances, bronchial hyper-responsiveness to pharmacological agents such as histamine or methacholine is still present in asthmatic subjects when there is no bronchial obstruction. ${ }^{26}{ }^{27}$ We found that although 16 subjects had bronchial obstruction, a greater proportion (29 subjects or $41 \%$ of the 71 subjects) still had bronchial hyper-responsiveness. This figure has to be compared with three of 13 subjects $(23 \%)^{18}$ and nine of 24 subjects $(38 \%)^{19}$ who underwent bronchial responsiveness testing 12 years and eight months respectively after being exposed to chlorine and acetic acid.

The fact that all but four of our subjects had never taken anti-inflammatory preparations (inhaled corticosteroids) at the time of the follow up might reflect the natural history of reactive airways dysfunction syndrome. Anti-inflammatory preparations may have affected the behaviour of the condition. It is unlikely that smoking affected our results as there were no differences in the distribution of smokers, ex-smokers, and non-smokers among those with and without bronchial 
obstruction or hyper-responsiveness. We were unable to detect a difference in the number of acute symptomatic accidental exposures (referred to as puffs by the workers) and the presence or absence of bronchial obstruction or hyper-responsiveness. It is known that repeated exposure to high concentrations of chlorine can occur in paper mills. ${ }^{28} 29$ The number of accidental exposures is not necessarily related, however, to the likelihood of developing more functional sequelae. One large exposure may be as harmful as several smaller but still symptomatic episodes. The fact that all the subjects included in this survey experienced symptoms of cough or dyspnoea at the time of the initial exposure underlines that they had experienced at least one episode of acute accidental exposure. We were able to assess the severity of episodes by distinguishing between those that required a visit to the emergency room and those that did not. Subjects who had been to a hospital emergency room were more likely to be left with persistent bronchial hyper-responsiveness. The severity, therefore, of one or other of several episodes may be a more significant determinant of the likelihood of developing permanent functional sequelae than the number of episodes.

Many questions related to acute exposure to chlorine are still not answered. The physiopathology of the reaction is still unknown. A recent study ${ }^{30}$ suggests that lymphocytic infiltration of the bronchial layers, denudation of the mucosa, and thickening of the basement membrane are key pathological features. Subjects with reactive airways dysfunction syndrome also seem to show less reversibility after inhaling a bronchodilator ( $\beta 2$ adrenergic agent) than subjects with occupational asthma with a latency periodthat is, those who become progressively sensitised to a high or low molecular weight product. The effect of anti-inflammatory preparations on reactive airways dysfunction syndrome is unknown. An animal model would be useful in answering these questions. Finally, the time course of functional sequelae has yet to be described. In this respect, changes in airway calibre and bronchial responsiveness that were documented 18 to 24 months after the end of exposure in this study may well not be permanent. A longer follow up is necessary to examine this specific point.

We thank medical student Josée Jetté for collecting the information. We are grateful to Katherine Tallman for reviewing mation. We are grateful to Katherine Tallman for reviewing Université de Montréal School of Medicine and the Fonds de la recherche en santé du Québec.

1 Ferris BG, Burgess WA, Worcester J. Prevalence of chronic respiratory disease in a pulp mill and a pape mill in the United States. Br F Ind Med 1967;24:26-37.

2 Ferris BG, Puleo S, Chen HY. Mortality and morbidity in a pulp and a paper mill in the United States: a ten year follow up. Br ₹ Ind Med 1979;36:127-34.
3 Brooks SM, Weiss MA, Bernstein IL. Reactive airways dysfunction syndrome (RADS). Persistent asthma syndrome after high level irritant exposures. Chest 1985; 88:376-84.

4 Bernstein DI, Bernstein IL, Malo JL, Chan-Yeung M. Definition and classification. In: Bernstein IL, ChanYeung M, Malo JL, Bernstein DI, eds. Asthma in the workplace. New York: Marcel Dekker, 1993, 1-4.

5 Murphy D, Fairman R, Lapp NL, Morgan WKC. Severe airways disease due to the inhalation of fumes from cleaning agents. Chest 1976;69:372-6.

6 Charan NB, Myers CG, Lakshminarayan S, Spencer TM. Pulmonary injuries associated with acute sulfur dioxide inhalation. Am Rev Respir Dis 1979;119:555-60.

7 Hasan FM, Geshman A, Fuleihan FJD. Resolution of pulmonary dysfunction following acute chlorine exposure. Arch Environ Health 1983;38:76-80.

8 Härkönen $\mathrm{H}$, Nordman $\mathrm{H}$, Korhonen $\mathrm{O}$, Winblad I. Long-term effects of exposure to sulfur dioxide. Am Rev Respir Dis 1983;128:890-3.

9 Flury KE, Ames DE, Rodarte JR, Rodgers R. Airway obstruction due to inhalation of ammonia. Mayo Clin Proc 1983;58:389-93.

10 Rajan KG, Davies BH. Reversible airways obstruction and interstitial pneumonitis due to acetic acid. $\mathrm{Br} \mathcal{F}$ Ind $\mathrm{Med}$ 1989;46:67-8.

11 Boulet LP. Increases in airway responsiveness following acute exposure to respiratory irritants. Reactive airway dysfunction syndrome or occupational asthma? Chest 1988;94:476-81.

12 Luo JC, Nelsen KG, Fischbein A. Persistent reactive airway dysfunction syndrome after exposure to toluene diisocyanate. Br $\mathcal{F}$ Ind Med 1990;47:239-41.

13 Chester EH, Gillespie DG, Krause FD. The prevalence of chronic obstructive pulmonary disease in chlorine gas chronic obstructive pulmonary disease in chir

14 Enarson DA, Maclean L, Dybuncio A, Chan-Yeung M, Grzybowski S, Johnson A, et al. Respiratory health at a pulpmill in British Columbia. Arch Environ Health 1984;39:325-30.

15 Kaufman J, Burkons D. Clinical, roentgenologic, and physiologic effects of acute chlorine exposure. Arch Environ Health 1971;23:29-34.

16 Ploysongsang Y, Beach BC, DiLisio RE. Pulmonary function changes after acute inhalation of chlorine gas. South Med $71982 ; 75: 23-6$.

17 Charan NB, Lakshminarayan S, Myers GC, Smith DD Effects of accidental chlorine inhalation on pulmonary function. West 7 Med 1985;143:333-6.

18 Schwartz DA, Smith DD, Lakshminarayan S. The pulmonary sequelae associated with accidental inhalation of chlorine gas. Chest 1990;97:820-5.

19 Kern DG. Outbreak of the reactive airways dysfunction syndrome after a spill of glacial acetic acid. Am Rev Respir Dis 1991;144:1058-64.

20 Courteau JP, Cushman R, Quévillon M, Chartrand A Bouchard F, Bhérer L. A survey of construction workers repeatedly exposed to chlorine over a three month period in a pulpmill. I. Exposure and symptomatology. Occup Environ Med 1994;51:219-24.

21 Burney PGJ, Laitinen LA, Perdrizet S, Huckauf $H$ Tattersfield AE, Chinn S, et al. Validity and repeatability of the IUATLD (1984) bronchial symptoms questionnaire: an international comparison. Eur Respir $f$ tionnaire: an

22 American Thoracic Society. Standardization of spirometry-1987 update. Am Rev Respir Dis 1987;136 1285-307.

23 Cockcroft DW, Killian DN, Mellon JJA, Hargreave FE Bronchial reactivity to inhaled histamine: a method and clinical survey. Clinical Allergy 1977;7:235-43.

24 Knudson RJ, Lebowitz MD, Holberg CJ, Burrows B Changes in the normal maximal expiratory flow-volume
curve with growth and aging. Am Rev Respir Dis 1983; curve with

25 Malo JL, Pineau L, Cartier A. Reference values of the provocative concentrations of methacholine that cause $6 \%$ and $20 \%$ changes in forced expiratory volume in one second in a normal population. Am Rev Respir Di 1983;128:8-11.

26 Hargreave FE, Sterk PH, Ramsdale EH, Dolovich J, Zamel $N$. Inhalation challenge tests and airway responsiveness in man. Chest 1985;87:202S-6S.

27 O'Byrne PM. Asthma as an inflammatory disease. New York: Marcel Dekker, 1990

28 Kennedy SM, Enarson DA, Janssen RG, Chan-Yeung M. Lung health consequences of reported accidental chloLung health conseguences of reported accidental chlorine gas exposures among

29 Salisbury DA, Enarson DA, Chan-Yeung M, Kennedy SM. First-aid reports of acute chlorine gassing among SM. First-aid reports of acute chlorine gassing among
pulpmill workers as predictors of lung health consepulpmill workers as predictors of lun
quences. Am $\mathcal{F}$ Ind Med 1991;20:71-81.

30 Gautrin D, Boulet LP, Boutet M, Dugas $M$, Bhérer L, L'Archevêque J, et al. Is reactive airways dysfunction syndrome (RADS) a variant of occupational asthma? Allergy Clin Immunol (in press). 